\title{
Fabio Capra
}

Arquitecto (2006) y magíster Scientiarum en Diseño Arquitectónico (2013), ambos títulos de la Facultad de Arquitectura y Urbanismo de la Universidad Central de Venezuela, donde labora como profesor de la Cátedra de Diseño Arquitectónico y coordinador de la Maestría en Diseño Urbano del Instituto de Urbanismo. Paralelamente se desarrolla como artista plástico.caprafabio@gmail.com.

ISNN 1666-6I86. Volumen 17 N. 17 (Noviembre de 2014) Pp. 047-070 - Recibido: 30-07-I3.Aprobado: 20-05-I4 


\title{
Resumen
}

En un constante debate entre condiciones aparentemente enfrentadas, el autor contrapone varias características del paisaje urbano para profundizar en el entendimiento de la Caracas actual. Un proceso eminentemente interpretativo permite ver la ciudad a partir de una experiencia de diario sufrimiento y disfrute. El desarrollo toma en cuenta las diferentes escalas de aproximación, la relación entre las edificaciones y el vacío, y el papel del verde en la ciudad. Poco a poco se hará evidente el nivel de descuido en el que prevalece el paisaje caraqueño, alimentado por una escasa atención a la pequeña escala, el cúmulo de intervenciones individualistas y el descuido del componente natural. Las reflexiones finales plantearán el concepto de paisaje como una noción compleja que requiere ser atendida desde diferentes perspectivas.

\section{Palabras clave}

Ciudad, arquitectura, diseño urbano, paisaje, paisaje urbano.

\section{THE DEBATE ON THE CONTRADICTIONS OF CONTEMPORARY URBAN LANDS- CAPE. THE CASE OF CARACAS}

\begin{abstract}
$\underline{\text { Abstract }}$
In the ongoing debate between seemingly conflicting conditions, the author contrasts several features of urban landscape to dig deeper into the understanding of the current Caracas. An interpretative process allows viewing the city from a daily perspective of joy and suffering. The process takes into account different scales of approach, the relationship between buildings and emptiness, and the role of green in the city. Gradually the carelessness of Caracas's urban landscape becomes evident, fed by little attention to the small scale, the clustering of individualistic interventions and the neglect of the natural component. Final considerations will show the urban landscape as a complex reality that requires that it be addressed from different perspectives.
\end{abstract}

Keywords

City, architecture, urban design, landscape, urban landscape. 


\section{INTRODUCCIÓN}

En los últimos años, el autor ha desarrollado un trabajo de investigación que analiza y se adentra en el estudio de la noción de límite en el ámbito de la arquitectura y el diseño urbano. El límite que, con referencia a las múltiples escalas y situaciones posibles, se presenta en forma de linderos, límites de propiedad que definen los lotes o parcelas, y que en algunos casos han ido tomando cuerpo con el paso del tiempo. En ciudades como Caracas, donde, a raíz de una galopante inseguridad, el propietario ha ido construyendo rejas y muros en los bordes de su respectiva parcela, cortando, o al menos dificultando, las relaciones entre el ámbito privado y el público (figura 1). Aunque esta situación es de suma importancia, la materialización de estos límites ha tenido otras consecuencias de peso: la anárquica intervención de la ciudad con planos que tienden a la verticalidad, una intensa fragmentación y un marcado deterioro del paisaje urbano (término sobre el cual se profundiza más adelante en este trabajo). En la tarea de desarrollar este último punto, el problema ha adquirido significación propia y se ha traído a debate por medio del presente texto.

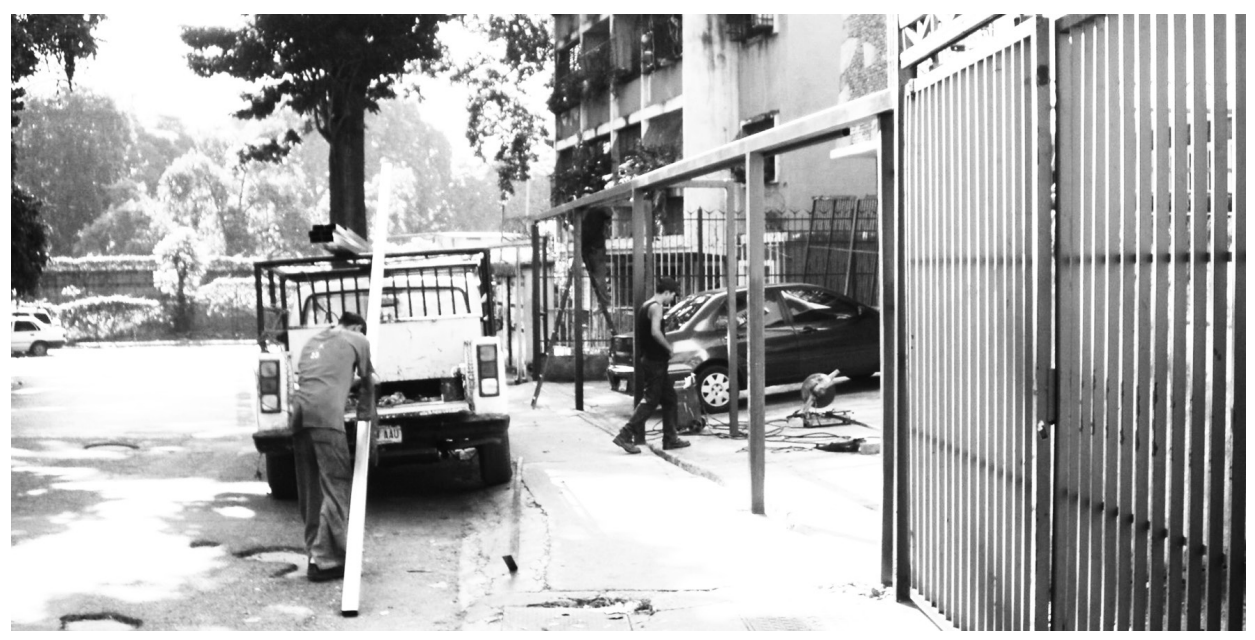

Figura 1. Materialización de los linderos en Caracas a través de rejas y muros Fuente: fotografía del autor

Como marco contextual es necesario hablar un poco más de Caracas, capital de Venezuela, ubicada en el centro-norte del país, a tan solo quince kilómetros de la costa del Mar Caribe. 
Se extiende este-oeste a través de un valle siempre escoltado por una inmensa cordillera de verde perpetuo: el Parque Nacional El Ávila. La topografía, ondulante, permite tener visuales imponentes de la ciudad desde diferentes puntos, lo que contribuye constantemente a enriquecer las imágenes presentes en la memoria colectiva (figura 2). Cuando se observa más de cerca, existe mucho que debatir, el ordenamiento urbano ha sido históricamente fragmentado y pocas veces aplicado a plenitud: la ciudad de los proyectos inconclusos. Al mismo tiempo, las difíciles circunstancias por las que pasa actualmente el país han hecho que sus habitantes se preocupen cada vez más por la salvaguarda y el bienestar propio que por contribuir al colectivo. Una ciudad muy noble, pero también muy maltratada.

Figura 2. Valle de la ciudad de Caracas visual desde Valle Arriba

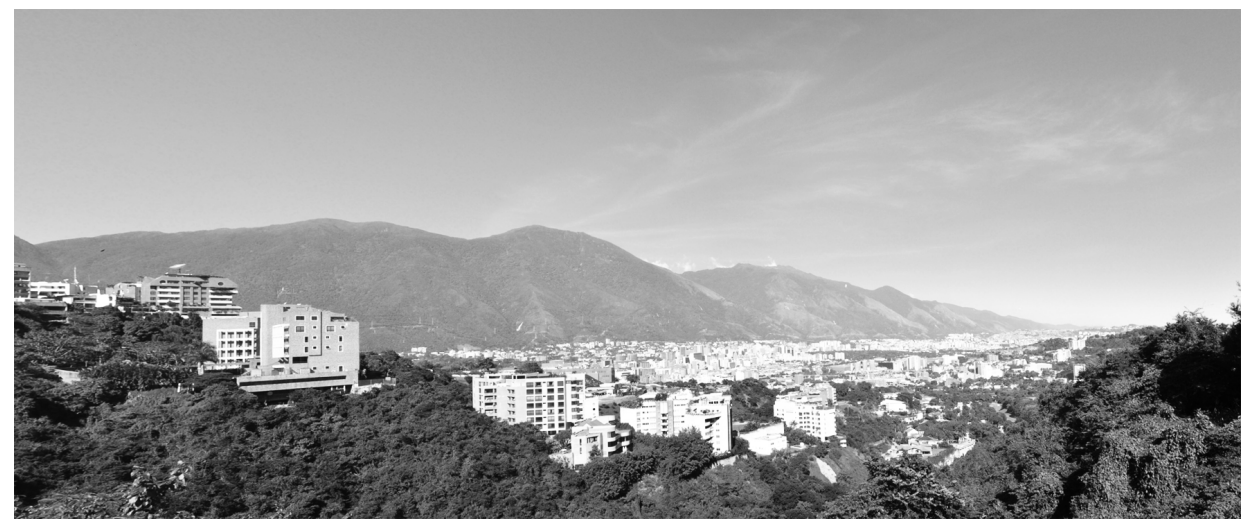

En general, la noción de paisaje urbano resulta un concepto evocador en sí mismo; puede contener virtudes importantes en las imágenes que construye, pero, cuando no es bien tratado, igualmente puede tornarse una certera representación de las dimensiones que encierra; tal vez ese sea el caso de Caracas. Ciudad en la que, se presume, tiene lugar una serie de contradicciones que han impulsado este segmento de la investigación: fragmentación del tejido urbano (Herrera Napoleón, 2005; Puchetti, 2004; Von der Heyde, 2007), débil configuración de espacios públicos (CARABALlo, 2004), accionar independiente y desconectado de las edificaciones (LASALA, 2007; LASALA, 2011) y la escasa o monótona incorporación de la vegetación.

En este sentido, este trabajo plantea la necesidad de indagar sobre las posibilidades proponiendo un camino contrario, que vislumbre nuevas posibilidades de intervención en el 
paisaje urbano que atiendan particularmente a la pequeña escala, cuidando el diálogo y los espacios vacíos entre los objetos construidos, e incorporar la exuberante vegetación existente en la ciudad como recurso de diseño y planificación.

Para avanzar sobre estas hipótesis, se plantea ahondar en la comprensión de temas resaltantes del paisaje urbano local, establecer las diferencias entre las condiciones actuales de la ciudad de Caracas con un conjunto determinado de estrategias de actuación y concretar una serie de recomendaciones sobre los caminos que seguir para mejorar la situación existente.

Con respecto a los procesos llevados a cabo para alcanzar estos horizontes, todo el trabajo se desarrolla en el marco de la hermenéutica, por medio del círculo hermenéutico entendido como un pensamiento que desplaza su atención de manera cíclica entre las partes y el todo para aumentar el nivel de comprensión con cada desplazamiento (MARTíNEZ, 2010). Se considera que las partes no son necesariamente fragmentos, sino unidades posibles de entenderse por sí mismas, lo que facilita el estudio inicial por separado mientras se mantiene la idea del todo como un concepto relativo y en interdependencia con los puntos estudiados (Pérez de Tudela Velasco, 1992). En su aplicación, se define como el todo al paisaje urbano - objeto central de investigación-, y las partes, a los diferentes componentes y tipos de relación que se reconocen durante el desarrollo de la investigación.

Para el desarrollo de este trabajo, y respondiendo a la estructura propuesta, se han establecido cuatro puntos: Anotaciones sobre el paisaje introduce el debate y algunas consideraciones generales sobre el tema; Lejos vs cerca. La dualidad de la escala confronta la distancia como factor determinante en la percepción del paisaje urbano; Lleno vs vacío. Lo urbano en la interacción de los objetos contrapone la importancia de las edificaciones y el espacio público en la construcción del paisaje; Verde vs gris. Relación entre la ciudad y la naturaleza discute la importancia de la naturaleza dentro de la ciudad y cómo esta puede colaborar para brindar mejores condiciones de vida. Por último, se abrirá espacio para unas reflexiones generales y otras específicas sobre Caracas.

\section{ANOTACIONES SOBRE EL PAISAJE}

La presente reflexión comienza por ahondar en el concepto de paisaje, porque se considera objeto central de estudio, pero también "[...] porque se corre el riesgo de que una consideración tan compleja como esta sea tratada simplemente, es decir, caricaturizado". (VELASCO Romano, 2003: 30), especialmente cuando se parte de reflexionar desde un paisaje tan descuidado o escasamente considerado como el que se vive en las calles de Caracas. 
En términos muy generales, es entendido como una extensión de terreno que se ve desde un sitio (DRAE, 2001), definición en la que se pueden reconocer dos ideas básicas: se aprehende a través del sentido de la vista y está asociado a la distancia; se entiende además como un espacio que no se habita (figura 3). "La visión más evidente del paisaje es visual, estética, subjetiva e individual, y se entiende que el uso del concepto fue desarrollado y utilizado como una categoría entendida bajo la perspectiva del manejo del espacio" (Aguilar Bellamy, 2006: 7). Al estar asociado intrínsecamente a la percepción de un sujeto, ya se abre un abanico de interpretaciones, y su aprehensión por medio del sentido de la vista sugiere una estrecha relación con el espacio físico.

Figura 3.

Representación de la noción de paisaje. Gran

Cañón, EE. UU.

Fuente: fotografia del

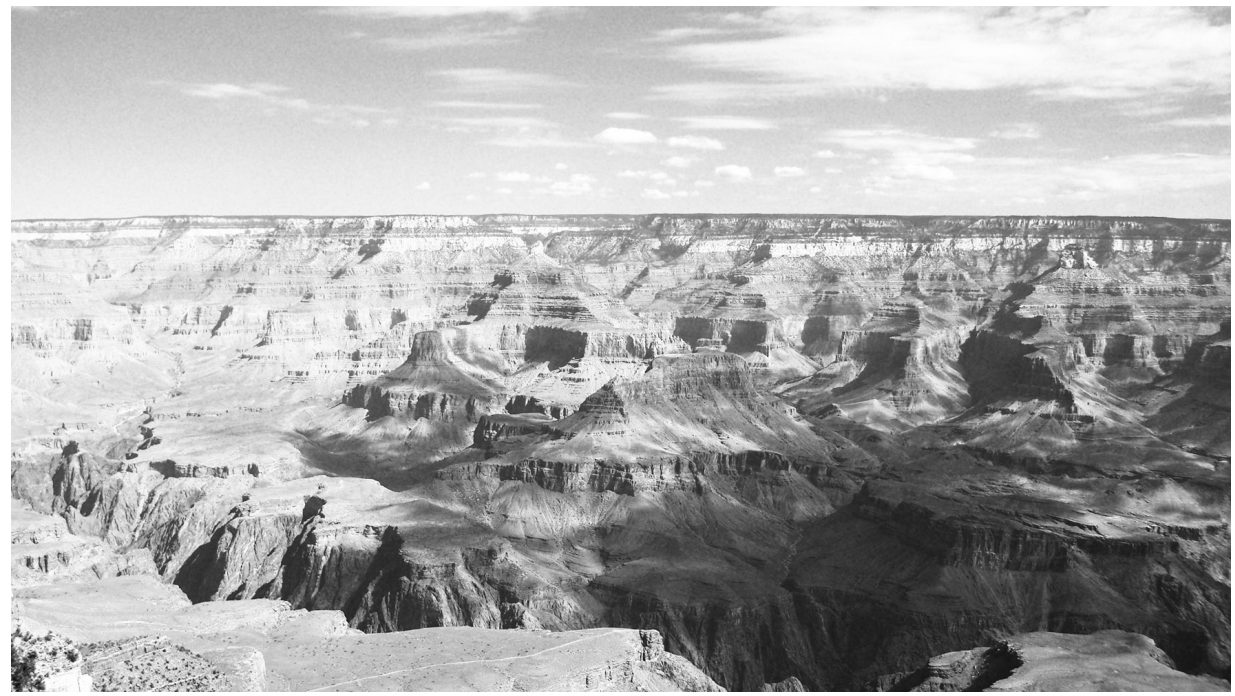

A diferencia de la imagen que podría transmitir una fotografía o un cuadro, el paisaje es esencialmente dinámico, sobre todo cuando se trata de versiones urbanas en las cuales las personas inciden intensa y constantemente en su imagen final. En ellos, la cultura se mezcla con el medio natural para producir paisajes únicos en cada una de las ciudades del mundo. En pocas palabras: "El paisaje urbano es una realidad fisico-espacial y una interpretación que hacemos de ella. Se integra a nuestra vida a partir de la percepción y capacidad para asociarla con significados, es por tanto objetivo y subjetivo" (BRICEÑo; Owen; Contreras, 2010: 398) (figura 4). 


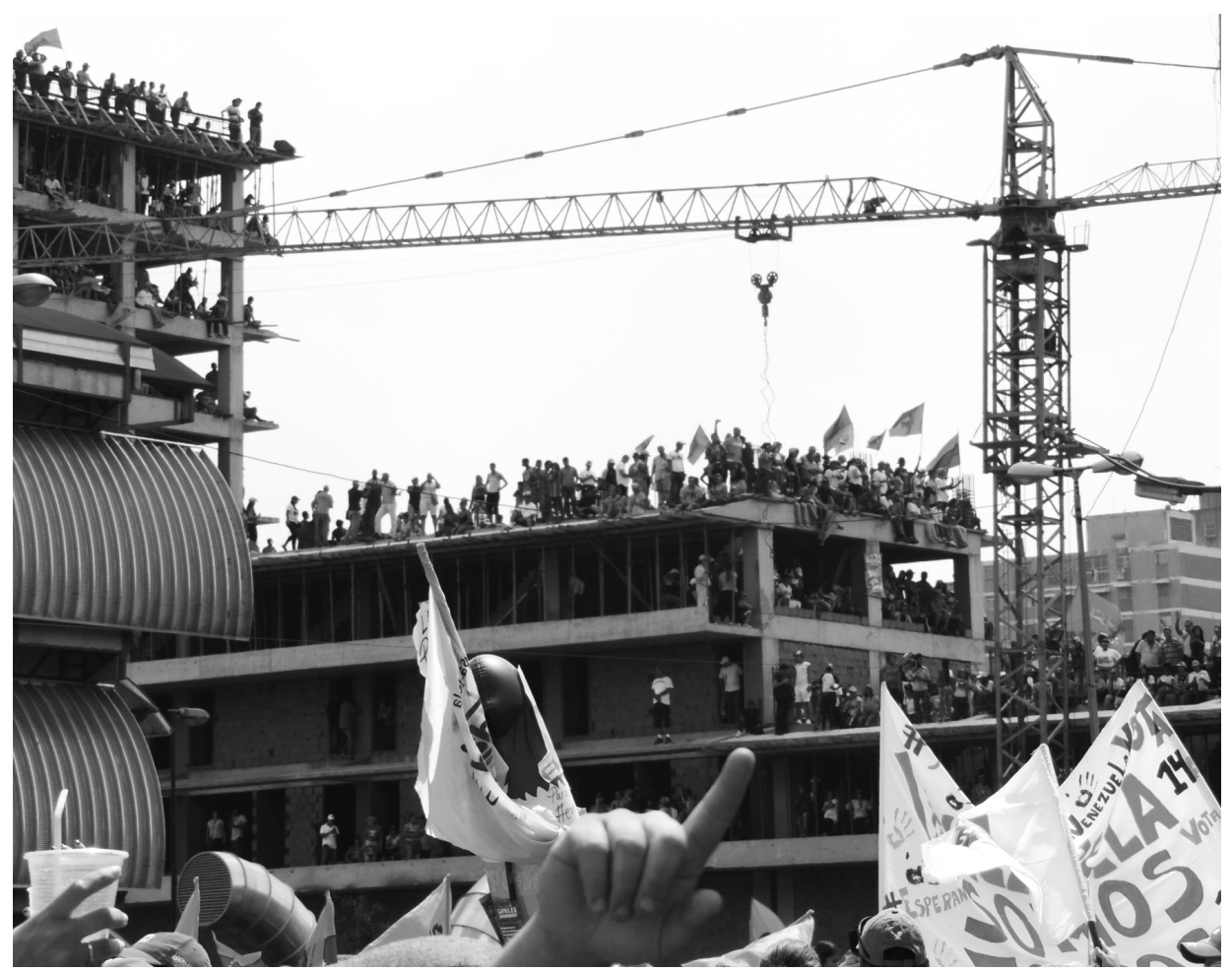

Figura 4. El paisaje urbano en constante transformación Fuente: fotografia ERIKA FRANCO

A partir de estas consideraciones, se han seleccionado algunos puntos especialmente resaltantes, sobre todo cuando se considera el caso de estudio: la relación de escala, la condición de vacío y la presencia del ámbito natural. Estos puntos se presentan con fuerza al final del ensayo de EDUARD BRU (1997: 26) titulado La mirada larga, que utiliza para introducir la exposición Nuevos paisajes. Nuevos territorios, del cual se extrae el siguiente segmento:

"El Landscape, tal como lo queremos ver aquí, no tiene relación con la escala, no es necesariamente la arquitectura de los espacios grandes y vacios, o abiertos, o 'verdes', ni 
tampoco el control cientificista de los posibles estropicios que pueden causar las grandes construcciones. Pudo definirse en un principio aproximadamente así, pero ha cristalizado en arquitectura. Una arquitectura que se caracteriza por atender tanto a lo que está entre las cosas como a las cosas en sí mismas: el espacio público, -un salón doméstico, una plaza, una terraza-, es, por tanto con frecuencia su objeto”.

¿Cuál es la relación del paisaje con la escala? ¿Es el paisaje una sumatoria de objetos? ¿Se construye a partir del vacío entre ellos? ¿Qué papel juega la vegetación? Y particularmente, ¿qué sucede con estas interrogantes en el contexto caraqueño?

\section{LEJOS VS CERCA. LA DUALIDAD DE LA ESCALA}

Son varios los factores que afectan la posible aproximación hacia el paisaje, pero, así como se evidenciada en las notas de EDUARD BRU, la distancia juega un papel central. Por ejemplo: "[...] cuando nos acercamos al interior de la ciudad, ya sea por aire o por tierra, tenemos una sensación y concepto diferente del paisaje urbano; a medida que nos aproximamos a ella vamos encontrando diferentes imágenes y la escala de apreciación se torna cada vez más detallada" (PÉrEz, 2000: 34). El paisaje no deja de existir con la aproximación, sigue ahí, pero cambia, se reforma, se especifica (figuras 5 y 6).

Figura 5. Paisaje-Urbano desde lejos. New York, EE. UU. Fuente: fotografia del autor

\section{Figura 6. Paisaje-Urbano desde cerca. Budapest,}

Fuente: fotografia Hungría
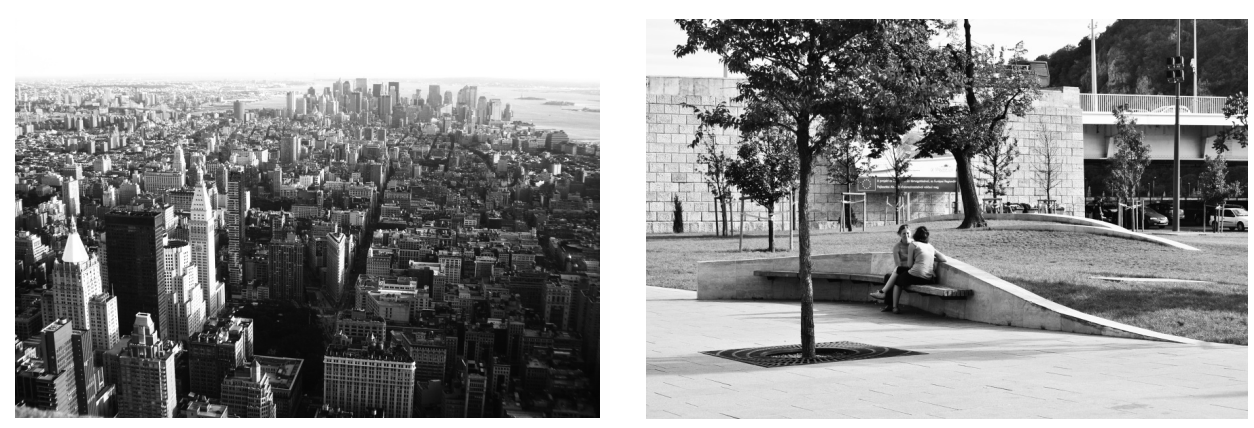

Según la distancia desde la que se considera, el paisaje atiende a diferentes lógicas. De lejos, se construye a través de la sumatoria de una inmensa cantidad de eventos, y la naturaleza tiene un peso enorme en el resultado final. Igualmente, las particularidades, para bien 
o para mal, son poco notables, y se funden en una idea global. Los ciclos de transformación que van más allá de la noche y el día son lentos. De cerca, la situación es muy distinta, las acciones tienen un peso mayor en el resultado final a través de circunstancias más evidentes. "Los diferentes elementos físicos conforman los decorados de los cuadros y escenas en las que los ciudadanos y habitantes de la ciudad desempeñan el papel de actores que dan vida, ejecutan e interpretan el 'teatro' de la cotidianidad de la vida urbana que se distribuye a lo largo del espacio y del tiempo de la urbe [...]" (Fernández GutiérRez, 2003: 475). La participación de las personas cobra mayor presencia, y la interacción con estos espacios es constante, recurrente, el escenario de lo cotidiano.

En el caso de Caracas, la dualidad de la escala se percibe de una forma muy peculiar, y plantea realidades contradictorias. Es muy distinto el recuerdo que se lleva el visitante que la observa desde el mirador, que el del ocupante permanente, que la recorre día a día entre sus más endémicos callejones. Sobre este tema, en un capítulo denominado precisamente El paisaje de la ciudad de Caracas, ANA LASALA (2007: 67) expone esta realidad contradictoria: "Desde lo lejos y desde lo alto se podría decir que la calidad del paisaje caraqueño está garantizada. El atractivo de la geografía de la ciudad y la importante presencia de la gran montaña al norte, el Ávila, conforman un seductor panorama en el que los elementos protagónicos que lo constituyen actúan como una serie de eventos que ubican y sitúan a los habitantes a lo largo del valle"; mientras que, por otro lado, la experiencia diaria brinda un panorama distinto: "Es a una distancia más corta desde donde se observa la continua aparición de muros, rejas, vallas publicitarias, automóviles, construcciones temporales y multitud de obstáculos físicos y visuales. Es aquí donde se puede percibir el mayor conflicto en relación con la imagen de nuestra ciudad". La división, el aislamiento y el deterioro suelen ser protagonistas. Situación especialmente delicada cuando nos encontramos con una ciudad ahogada en soluciones temporales e insuficientes (figura 7).

Las grandes perspectivas de la ciudad son tal vez las imágenes más próximas al concepto básico de paisaje urbano, pero aquí se plantea ver el problema desde un punto de vista más completo que considera las diversas escalas. Dejar un poco de lado las postales protagonizadas por amplias visuales de un valle que parece nunca envejecer (figura 8), para atender las descuidadas condiciones de las calles, urbanizaciones y barrios; responsabilidad directa del diseño urbano, el paisajismo y la arquitectura (figura 9). Una deuda con el paisaje de cerca. Un compromiso para enriquecer sus recorridos y construir rincones que motiven una favorable interacción entre los habitantes y el paisaje urbano que atestiguan. 
Figura 7. Fotografia dirigida a evidenciar la diferencia que puede apreciarse en Caracas dependiendo de la distancia de la observación. Visual desde Chulavista Fuente: fotografia del autor

Figura 8. Caracas desde lejos. Visual desde el Parque El Calvario Fuente: fotografia ERIKA FRANCO
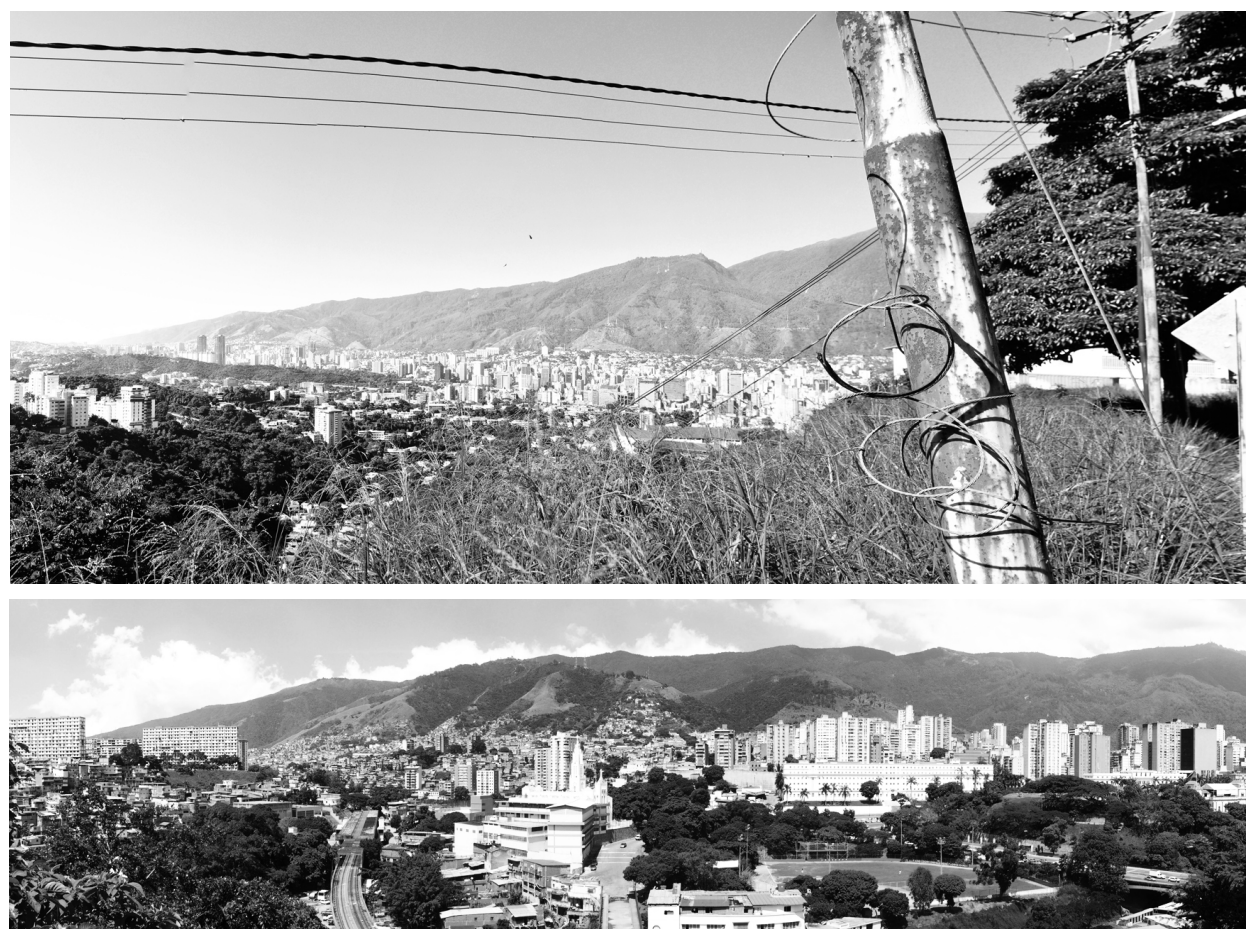

\section{LLENO VS VACÍO. LO URBANO EN LA INTERACCIÓN DE LOS OBJETOS}

El segundo punto de debate sobre el paisaje urbano hace referencia nuevamente al paisaje de EDUARD BRU que se cita en el primer capítulo, y tiene que ver con ese atender a lo que está entre las cosas además de las cosas en sí mismas. Sobre este tema - el valor del vacío en la condición urbana- SiLverio GonzÁlez (2005: 210) afirma: "El sentido de la comunicación politizada, lo urbano, no es definible por nada objetivo, porque su misma definición remite a otros significados en un movimiento particular, en sucesivos saltos de apertura. Por eso el encuentro comunicativo de la polis simbólica es un hueco, un espacio, por donde se mueve la relación, se desplazan los sujetos en sus interpretaciones y acciones entre los objetos". Aunque el paisaje urbano se construya a partir de la organización de objetos, el escenario de la interacción será usualmente el espacio entre ellos. 


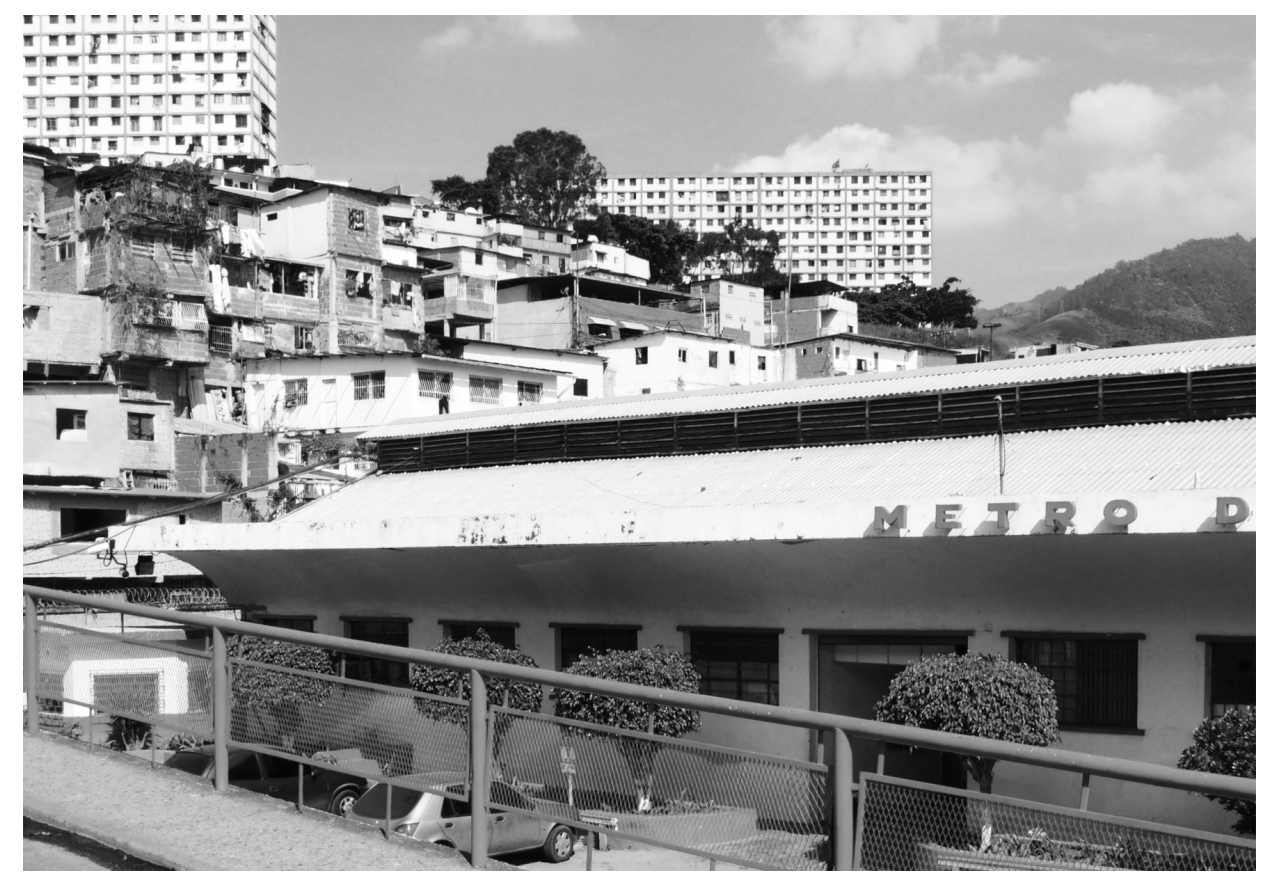

Figura 9. Caracas desde cerca. Barrio 23 de Enero

Fuente: fotografia ERIKA FRANCO

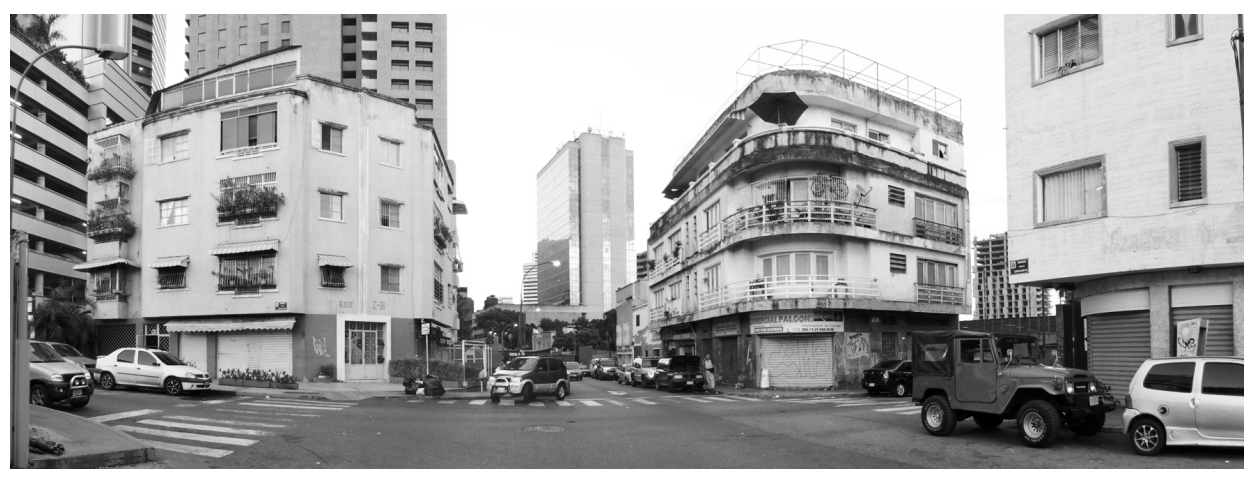

Figura 10. Caracas desde cerca. Urbanización Bolivar de Chacao Fuente: fotografia ERIKA FRANCO 
Al obviar esta condición, la especial atención que la arquitectura le brinda a las edificaciones suele traducirse en el descuido de la articulación entre ellas. "Cuando pensamos en el espacio, sólo miramos sus contenedores. Como si el propio espacio fuese invisible, toda la teoría para la producción de espacio se basa en una preocupación obsesiva por lo opuesto: la masa y los objetos, es decir, la arquitectura. Los arquitectos nunca pudieron explicar el espacio; el 'espacio basura' es nuestro castigo por sus confusiones" (KoOLHAAs, 2007: 9). En Caracas esta situación cobra fuerza en las llamadas Áreas de Crecimiento por Extensión, donde las manzanas no son cerradas y predominan las edificaciones aisladas (MARCANO, 1994). Al estar separadas, las construcciones tienen la oportunidad de alzarse en un completo desentendimiento del resto, el margen vacío entre unas y otras se utiliza como espacio de maniobra para absorber las diferencias y tiende a adquirir condiciones residuales. Estas situaciones se multiplican a lo largo de la ciudad convirtiendo muchos de estos vacíos en espacios intersticiales, los cuales suelen carecer de noción de lugar, presentarse como una incertidumbre para quien los recorre, ser indefinidos y comúnmente ocupados por lo anárquico (VON DER HeYde, 2007) (figuras 11 y 12).

Figura 11. Elevado como espacio intersticial. Santa Mónica, Caracas Fuente: fotografia del autor

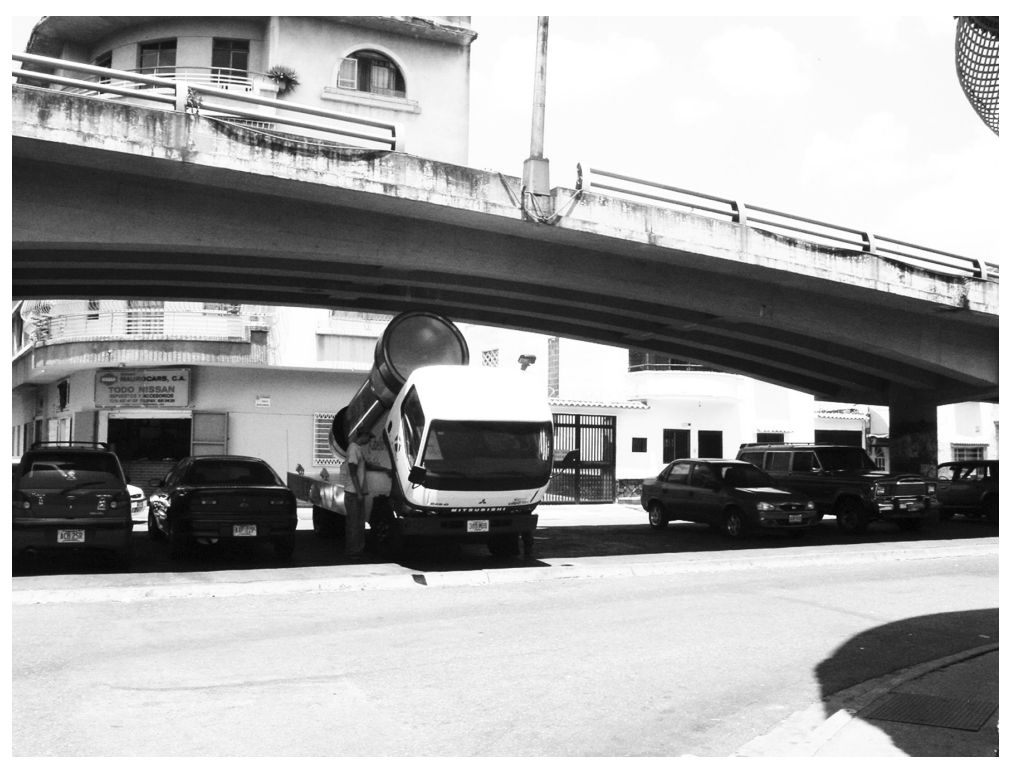


Las faltas asociadas al vacío en el paisaje urbano caraqueño no son solo cualitativas, las debilidades cuantitativas son alarmantes. "Caracas cuenta sólo con 1,5 m2 de áreas verdes/ hab. No existen condiciones para la movilidad peatonal (aceras amplias, iluminadas, limpias, con paradas de transporte público) y los sectores de barrios (donde vive una alta proporción de la población) no tienen ningún tipo de espacio público" (AlCALdía del ÁREA Metropolitana de CARACAs, 2011). Seguramente sea exagerado decir que no existe ningún tipo de espacio público en las zonas de barrios porque incluso las escaleras se convierten en punto de encuentro; pero igualmente los índices son alarmantes (figura 12).

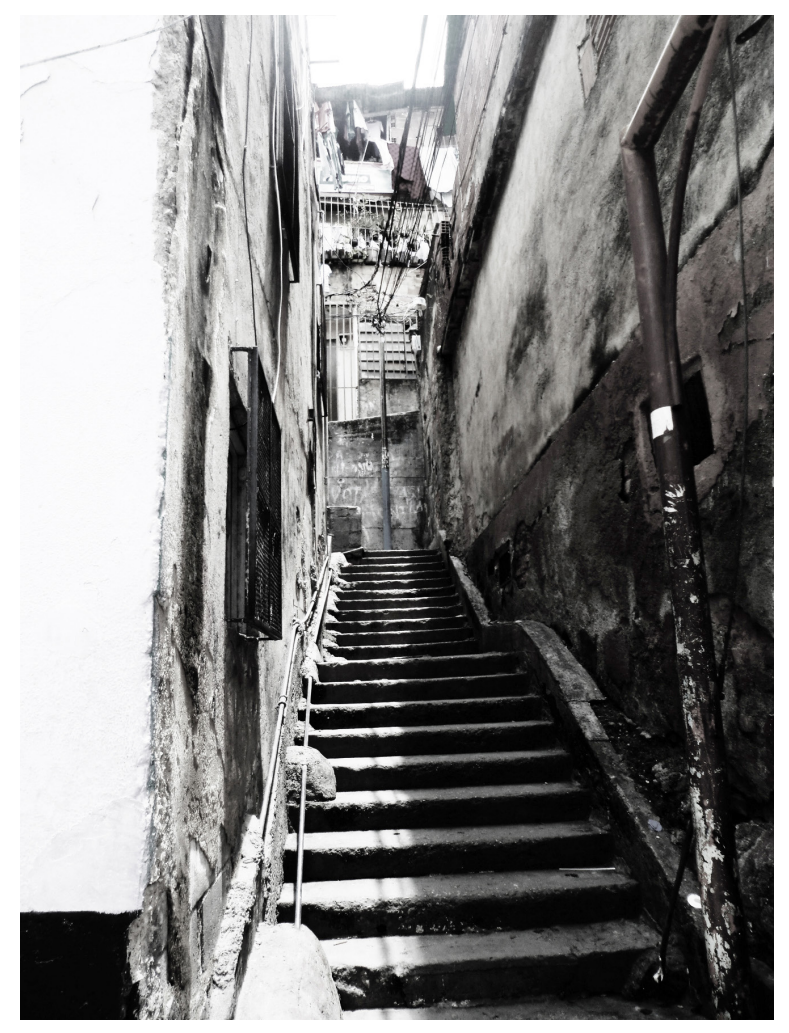

Figura 12. Escaleras como uno de los pocos espacios públicos en los barrios de Caracas. La Vega

Fuente: fotografía ERIKA FRANCO 
Los edificios existen, se construyen y autoconstruyen, pero el vacío, el espacio público, falta (figura 13). Se produce un importante desequilibrio en la composición del paisaje urbano, se debilita el vacío, el espacio para el intercambio social. Cuando escasea, es inadecuado o resulta amenazante, los niños son retirados de las calles para ser dejados en la televisión y los simuladores de juegos, debilitando el desarrollo de los rasgos sociales y la actuación en grupo (MARTínEZ, 2003), situación que no solo se presenta actualmente en la nación suramericana, sino que, probablemente, afectará los lazos de la sociedad del futuro.

Figura 13. Ocupación planificada y no planificada del tejido urbano en Caracas, que deja poco lugar al espacio público. Visual desde San Agustín Fuente: fotografia ERIKA FRANCO

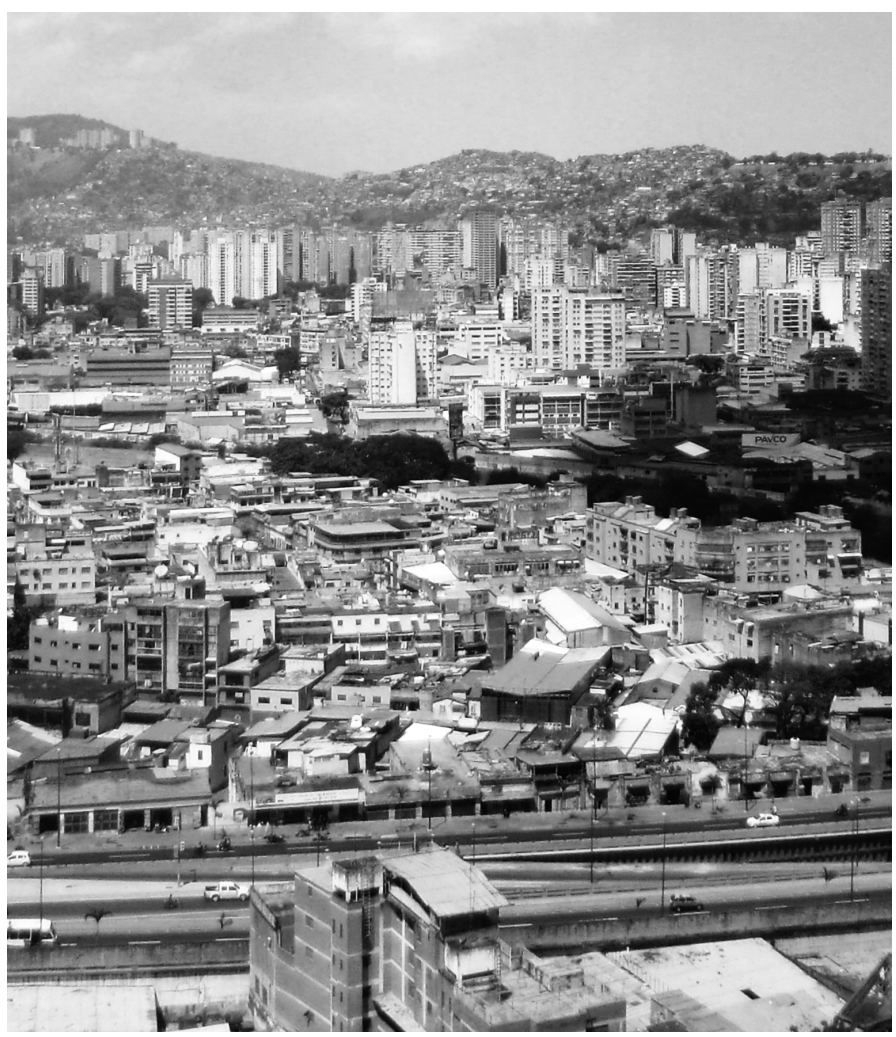


Para acondicionar el vacío, tomar en cuenta la interacción con los edificios es fundamental, ya que difícilmente el intermedio puede hacerse a sí mismo. Se construye o limita a partir de las piezas que entran en juego y, en la medida en que estas lo favorezcan, se torna más interesante y dinámico; por ejemplo: "Edificios grandes con fachadas largas, pocas entradas y pocos visitantes significan una dispersión efectiva de los acontecimientos. Por el contrario, el principio sería hacer piezas estrechas y muchas puertas" (GeHL, 2006: 105). Se actúa sobre las condiciones resultantes en el vacío, pero a partir de los objetos construidos. Los límites y espacios intermedios cobran un valor resaltante, sobre todo en los niveles más próximos a la calle, que intervienen directamente en el recorrido del peatón.

Al mismo tiempo que se entiende la importancia de los tres elementos —lleno, vacío y relación-, en Caracas los edificios llevan adelante un diálogo de sordos que promueven espacios intersticiales con poco que decir. El intercambio se desarrolla cuando las actividades, flujos y dinámicas, desde y hacia los edificios, son fructíferas. Para eso los límites entre el espacio público y privado deben constituirse en la transición que quebrante las lógicas ortodoxas. "El límite es un finis terrae, final de algo e inicio de lo desconocido. Esta es una idea arcaica de límites, una idea que, claramente, no es operativa en el espacio contemporáneo" (MATEO, 1995: 28-29). Lo realmente importante está del otro lado, porque el vacío requiere las edificaciones para activarse, y estas a su vez se alimentan de él como condición necesaria para su existencia.

\section{VERDE VS GRIS. RELACIÓN ENTRE LA CIUDAD Y LA VEGETACIÓN}

Aquí se contrastan dos elementos que han estado presentes durante todo el texto: la condición natural y la intervención humana. La naturaleza, entendida en toda su complejidad, conforma el estrato básico sobre el cual se asienta cualquier otra intervención; además, su cuidado es fundamental para minimizar el deterioro del medio ambiente.

Los factores naturales tienen en Caracas un papel protagonista. Aunque cuenta con un importante patrimonio arquitectónico, no es el peso de la cultura, la historia milenaria, el perfecto estetismo japonés o las aspiraciones intelectuales universales del Renacimiento lo que define nuestro horizonte arquitectónico, sino las inmensas dimensiones de una vegetación opulenta, de calores avasallantes y de lluvias que son torrentes, las que definen las nociones de las intervenciones arquitectónicas emplazadas en este lugar (PosANI, 1994). El manejo e incorporación de estos elementos es especialmente importante en la capital venezolana, ya que "[...] los principales aspectos felices de Caracas que señalan sus habitantes preceden a su fundador Diego de Losada" (VEGAS, 2007: 83). 
Son esas mismas características favorables las que impulsan el desarrollo habitacional en zonas próximas a la condición natural, sea en la constante búsqueda de la vista al Ávila o en la ocupación de urbanizaciones menos densificadas que han dejado colar al verde. El concepto de paisaje urbano dentro del contexto ambiental se refiere, por una parte, a la dicotomía ciudad-campo, es decir, a una relación entre el hombre, su cultura y la naturaleza; en este sentido, el valor del uso del paisaje se expresa en el nivel de integración entre el campo y la ciudad (PÉrEz, 2000).

El interés por una condición mixta: los servicios de la ciudad y las bondades de la naturaleza dicen mucho con respecto a los horizontes hacia los cuales dirigir la ciudad. Estos puntos no son opuestos ni contradictorios, pueden existir y alimentarse mutuamente. "Las tendencias observadas en el paisaje urbano se orientan a lograr una mayor integración y protección de áreas naturales dentro y fuera de la ciudad. El contacto funcional y visual con estas áreas, ha sido, es y deberá continuar siendo, una parte también consustancial a la herencia genética y evolutiva del hombre" (BRICEÑo; Owen; CONTRERAS, 2010: 401). En la medida en que se cambie la imposición por la ocupación de la geografía, y se incorpore el manejo constante de la naturaleza dentro de la producción arquitectónica, serán posibles intervenciones más próximas a los deseos de sus habitantes y a planes más sustentables de desarrollo.

En la nobleza del clima tropical, donde las plantas crecen con furor mostrando en cada rincón la presencia de la vida (figura 14), el esfuerzo necesario para utilizar esta variable no es más que el de canalizar sus energías a través de mínimos controles. Además, para alcanzar más que un acompañamiento verde, valdría la pena considerar al paisajismo como un elemento dinámico que participe activamente de la realidad urbana. Superar la condición contemplativa para construir espacios verdes que ayuden a disminuir las temperaturas, colaboren con las visuales, controlen y aprovechen las aguas de lluvia, etc. Así como no existe contención de taludes más sustentable que un árbol, tampoco existe mejor acondicionador de aire. "Caminante no hay camino, hace calor al andar; tanto, que el aire se convierte en margarina, las alcantarillas en parrillas, las fachadas en espejos, las aceras en sartenes" (VEGAS, 2007: 37). Conducir artificialmente los espacios verdes para enfrentar a las propias condiciones que nos presenta la naturaleza, nada que no se haya dicho antes, pero de especial importancia en un escenario tropical como el caraqueño.

La situación se torna más compleja que la simple multiplicación de los espacios verdes, ya que la atención al ámbito natural también implica cuidar las particularidades del clima y estrechar relaciones entre estas, la edificación y el espacio público que se diseña. “¿Dónde 
está el norte? Esta era la primera pregunta que Carlos Raúl Villanueva, con ese tono de voz suyo, entre ingenuo y burlón, le planteaba a sus estudiantes. Quienes lo acompañábamos en las correcciones de la Facultad de Arquitectura conocían muy bien el significado de esa pregunta. Era la pregunta por el contexto, por el clima, por la inclinación del sol, por las brisas y las lluvias, por la orientación y por las vistas, por la temperatura, por la geografia y la cosmografia" (PosAni, 1994: 53). Sabiduría que deja poco lugar a la duda, la arquitectura que crece distanciada de esta cúpula tropical está condenada a convertirse en esclava de la propia tecnología que la hizo posible.

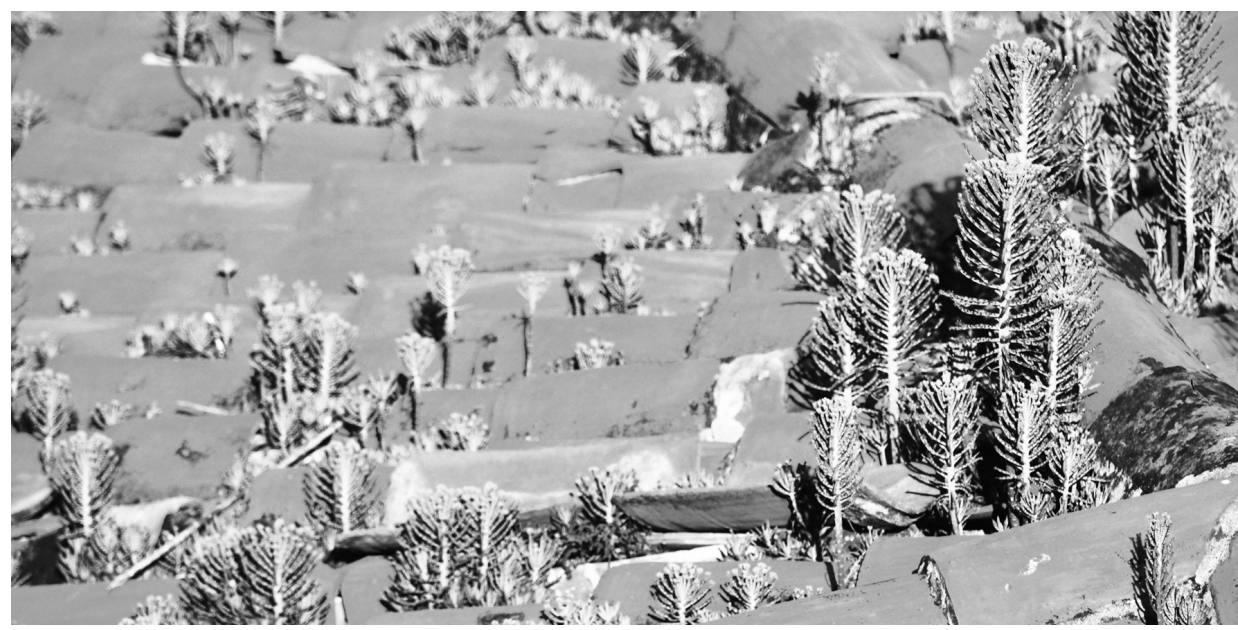

Existe otro factor fundamental para manejar con sabiduría la inclusión de la naturaleza dentro de la intervención humana: las alteraciones que hemos venido causando en el planeta. "La renovada preocupación por el ambiente, por los problemas ecológicos, por el reciclaje a distintas escalas, ha promovido la aparición de una actitud hacia lo natural más preocupada por su funcionamiento como sistema engranado con lo urbano" (CARABALLO, 2004: 80). El hecho de pensar verde o del diseño sustentable parece ya no ser solo una opción cuando se tiene en cuenta los índices de degradación y contaminación que llevamos adelante. Más allá de las múltiples dimensiones que considera la sustentabilidad, la incorporación activa de la naturaleza puede resultar un factor fundamental en el trato ecológico con el ambiente.

Cuaderno Urbano. Espacio, Cultura, Sociedad - Vol. 17 - N. ${ }^{\circ} 17$ (Noviembre de 2014) - Pp. 047-070 - ISNNI666-6I86
Figura 14. La vegetación que surge por sí sola en cada rincón. Los Chaguaramos, Caracas

Fuente: fotografia del autor 
El componente natural resulta así de especial importancia en cualquier contexto, y tiene la capacidad de potenciar la obra arquitectónica si se establecen relaciones más allá del mero aprovechamiento. Sobre este tema, y haciendo especial énfasis en el componente vegetal, Michael Sorkin (1998) dedica una de sus once tareas para enfrentar el diseño urbano específicamente al verde. Considera que la existencia de espacios verdes es un derecho fundamental de los ciudadanos, y los diseñadores urbanos deberían garantizar su existencia y variedad tanto en condiciones públicas como privadas. Al mismo tiempo, hace énfasis en superar la dicotomía casa-jardín y ciudad-parque, precisamente para impulsar esa variedad además de la cantidad.

Aunque no es una garantía, la inclusión del verde en relación e interacción con la arquitectura, como ornamento, acompañando los espacios de esparcimiento, ayudando a conllevar las condiciones climáticas, etc., podrá constituirse en un valioso componente del paisaje urbano que, al fin y al cabo, se posa sobre un estrato meramente natural. Además, en Caracas es importante resaltar que la vitalidad del trópico facilita el manejo de este elemento tan noble, especialmente abierto al diálogo y a una relación más simbiótica.

\section{CONTRASTES GENERALES. PREOCUPACIONES SOBRE EL PAISAJE}

Luego de tener en cuenta las particularidades del caso de estudio, es posible extrapolar un par de ideas sobre las preocupaciones que detonaron esta investigación.

El paisaje urbano es más que una imagen dibujada desde el mirador. Hace ya una década el paisajista JAUME BUSQUETS FÁBREGAS (1993) afirmaba: "Es urgente descartar, dentro del ámbito de la enseñanza, la idea de paisaje como sinónimo de vista panorámica, escenario natural singular o lugar de gran belleza, puesto que todas estas concepciones reflejan sólo parcialmente, e incluso de un modo muy subjetivo, el concepto de paisaje”. Es más que eso, el paisaje urbano es el accionar de la historia sobre la geografía (RIBAS y PIERA, 2003); el resultado del habitar, producción y dominio del territorio por parte de sus habitantes (Briceño; Owen; Contreras, 2010). El paisaje es lo que vemos todos los días al ir al trabajo, los juegos en plazas, los proyectos en construcción. La imagen estática es solo una representación simplista del paisaje urbano.

El paisaje urbano es más que la suma de sus componentes. Compuesto por árboles, ríos, edificaciones, calles, plazas, gente, etc., no se amalgama por proximidad. "Al mismo tiempo que la complejidad de la ciudad moderna exige continuidad, también proporciona un gran deleite: el del contraste y la especialización de las características individuales" (LYNCH, 
2008: 114). El paisaje urbano requiere considerar las fórmulas de relación a través de las cuales cada uno de los componentes ocupa su lugar, expresan sus valores, pero también interactúan y construyen noción de conjunto. Atender al paisaje urbano considerando el embellecimiento de pequeñas áreas verdes de la ciudad nos remontaría al siglo XVI (Kostoff, 1993). La impronta del presente obliga a verlo desde una perspectiva más integral, evitando las dicotomías público y privado, calzada y acera, que podrían debilitar su coherencia o desvincularlo. Enfatizar así las interacciones entre los diferentes componentes del paisaje urbano implica entenderlo como el posible diálogo entre todos los actores que hacen vida en las ciudades.

Aprehender el paisaje urbano llama a la participación central de la mirada. Podría pensarse que observar implica estar fuera de, pero, por el contrario, participar de la ciudad requiere convertirse en protagonista del mismo hecho observado.

\section{CONTRASTES PARTICULARES. CONSIDERACIONES FINALES SOBRE CARACAS}

A continuación, se presentan los frutos del cruce y la revisión transversal de los temas tratados hasta ahora, enfocándose en la ciudad de Caracas. Un esfuerzo por sintetizar y expresar las ideas más importantes.

La escala de aproximación se relaciona a la presencia de la vegetación. De lejos, la ciudad parece estar dominada por la naturaleza; de cerca, suele brindar una imagen opuesta. Adentrándose en sus calles, se va dejando de lado el atrayente paisaje lejano para verse cara a cara con una ciudad que parece olvidar el trópico; se descuidan los pocos espacios verdes; las flores quedan solo en manos de iniciativas particulares; los árboles sobreviven con apenas un mínimo cuidado. Pensar a futuro parece requerir incluir en cada uno de sus espacios públicos importantes representantes del escenario natural. Inyectarlo en sus calles como elemento contemplativo, como espacio de juego, del encuentro, y utilizarlo además como medio para dialogar con el impredecible clima del Caribe.

El vacio le brinda oportunidades al verde (figura 15). Es precisamente el vacío, en su condición de espacio público, generalmente quien juega un papel importante en el alojamiento de la vegetación. En su condición desocupada y en contacto con la tierra, se propicia el desarrollo de la naturaleza. Los edificios, por mucho que quieran fantasear con balcones, jardineras y techos verdes, no podrán alcanzar el soporte que el suelo brinda para el desarrollo de la naturaleza. 
Figura 15. El vacio en la ciudad como oportunidad para la vegetación. La Vega, Caracas Fuente: fotografía ERIKA FRANCO

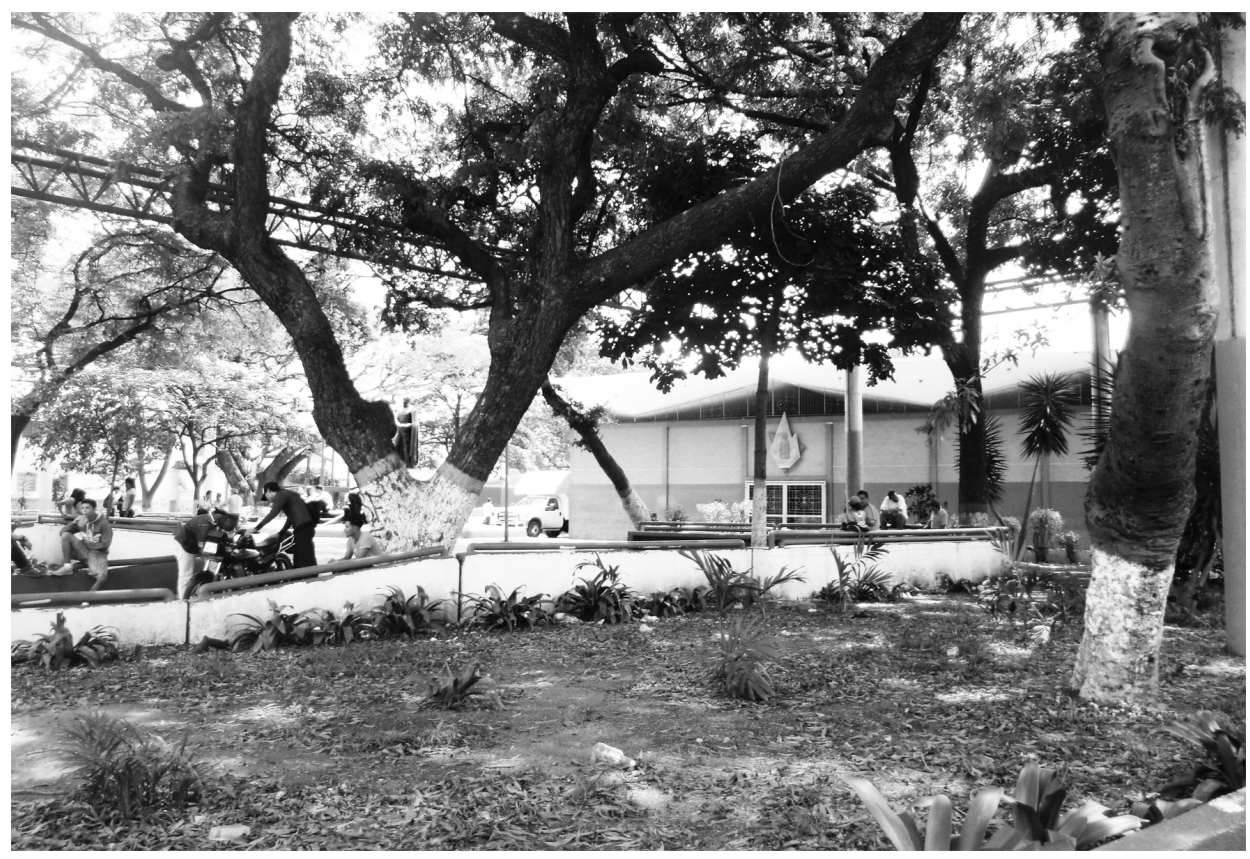

Existe la necesidad por atender la pequeña escala. Preocuparse por el habitar diario de la ciudad significa atender lo que está entre construcciones, evitar el aislamiento y la división. "Si ello se consigue, dejará de ser la calle una simple franja de asfalto bordeada de aceras. Podrá ser considerada como algo asociado a los edificios y producir, por medio de cambio de niveles, de escalas, de texturas y de general adecuación, un saludable efecto de sociabilidad y homogeneidad" (Cullen, 1974: 128). Superar la condición neutral del espacio público para transformarlo en un lugar para el consumo social, para ser interpretado, admirado y disfrutado como si fuera un parque de diversiones (KostofF, 1999). Para ello será necesario brindarle oportunidades a la ciudad, que los espacios públicos no se conviertan en la excepción, sino la regla que colonice los intersticios de la indiferencia. 
Las actuales condiciones del paisaje urbano tienen una responsabilidad compartida (figura 16). Si el paisaje urbano es el resultado de la interacción de sus componentes a través del tiempo, entonces todos - naturaleza, edificaciones, habitantes - han contribuido en el producto final. En primer lugar, las edificaciones se suelen instalar de manera independiente, poco vinculadas con su contexto, y caen fácilmente en una serie de piezas aisladas. Interactuar con el vacío implica considerar al edificio como incrustaciones hechas en un material, en lugar de un mueble colocado sobre una superficie (RUBY; RuBy, 2006). En segundo lugar, los habitantes han optado por estrategias individualistas: cada quien busca salvaguardar su posición desprestigiando el enriquecimiento colectivo. Por último, cuando se contrastan los temas, la legislación urbana asoma su cuota de responsabilidad. Al fin y al cabo, no ha existido una legislación y fiscalización que se preocupe por los temas aquí tratados con relación al paisaje de la ciudad.

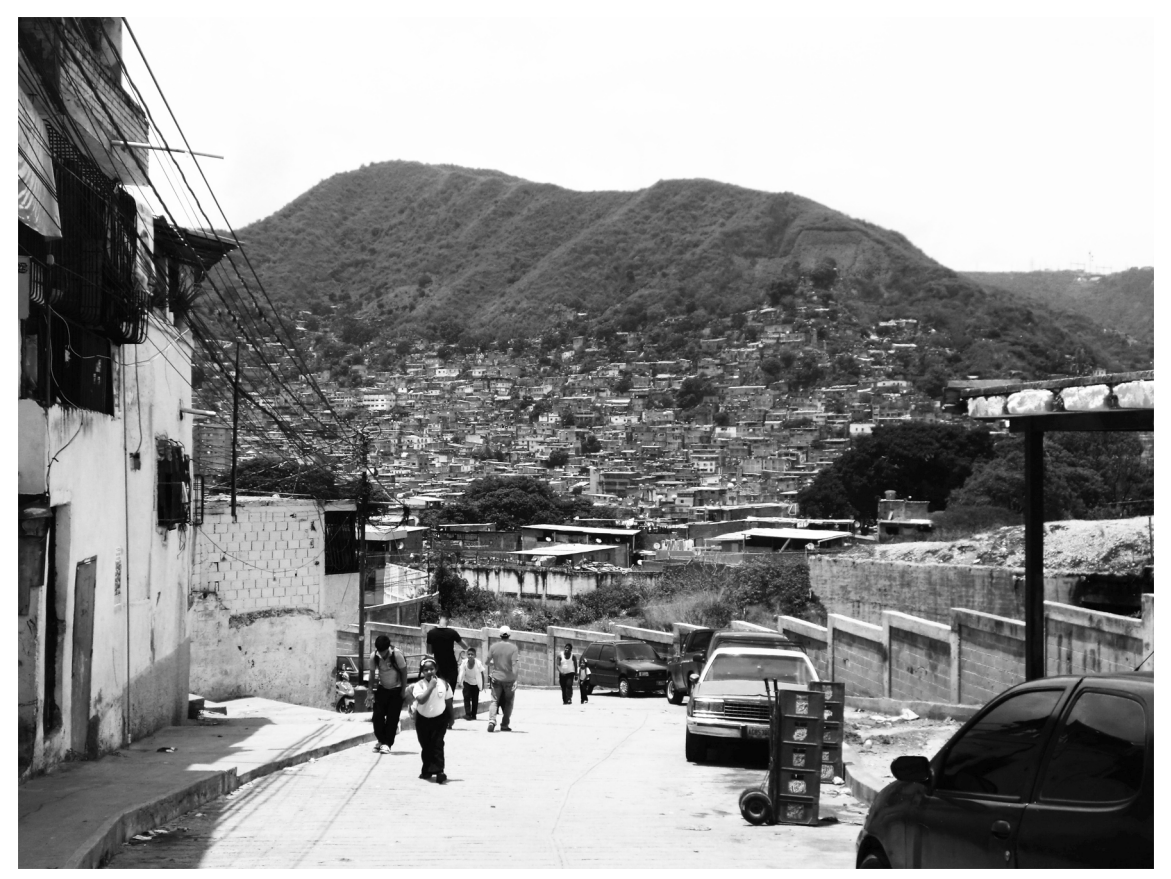

Figura 16. El paisaje urbano de Caracas como consecuencia del accionar de todos. Antímano

Fotografia: fotografía ERIKA FRANCO 
En pocas palabras, en Caracas parece difícil lograr un paisaje urbano coherente hoy en día. Si consideramos las reflexiones que se han hecho aquí: la necesidad de cuidar las múltiples escalas del paisaje urbano, atender la relación entre los objetos, el vacío y los demás actores urbanos, e integrar lo natural y lo artificial; entonces falta bastante camino por recorrer para que se concreten esas afirmaciones.

\section{BIBLIOGRAFÍA}

AGUILAR BELLAMY, Alexandra (2006). “Algunas consideraciones teóricas en torno al paisaje como ámbito de intervención institucional". En: Gaceta Ecológica. Secretaría de Medio Ambiente y Recursos Naturales. México D. F., México.

ALCALDÍA DEL ÁREA METROPOLITANA DE CARACAS (2011) Plan Estratégico Caracas Metropolitana 2020. Caracas, Venezuela.

BRICEÑO, Morella; OWEN, Mary; CONTRERAS, Wilver (2010). “Tendencias en la investigación y el diseño del paisaje urbano". En: Ecodiseño \& sostenibilidad. Valencia, España.

BRU, Eduard (1997). "La mirada larga". En: Nuevos paisajes, nuevos territorios. Actar/ MACBA, Barcelona.

BUSQUETS FÁBREGAS, Jaume (1993). "La lectura e interpretación del paisaje en la enseñanza obligatoria". En: Revista Aula de Innovación Educativa 19. Barcelona, España. CARABALLO, Alfredo (2004). "Genérico + Local: Mirada sobre la naturaleza de la esfera pública contemporánea”. Trabajo de grado Magíster Scientarium en Diseño Arquitectónico. Universidad Central de Venezuela. Caracas, Venezuela.

CULLEN, Gordon (1974) El paisaje urbano. Tratado de estética urbanística. Editorial Blume. Barcelona, España.

REAL ACADEMIA ESPAÑOLA (2001) Diccionario de la Real Academia Española, Vigésima segunda edición. Disponible en: http://lema.rae.es/drae.

FERNÁNDEZ GUITIÉRREZ, Fernando (2003). "El paisaje urbano de la ciudad de granada" En: Colección Mediterráneo Económico: "Ciudades, arquitectura y espacio urbano”. Caja Rural Intermediterrámea. Almería, España.

GEHL, Jan (2006) La humanización del espacio urbano. Editorial Reverté. Barcelona, España.

GONZÁLEZ, Silverio (2005). La ciudad venezolana. Fundación para la Cultura Urbana. Caracas, Venezuela.

HERRERA NAPOLEON, Carola (2005). "Híbridos urbanos. La expresiva conjunción 
de bordes heterogéneos". Trabajo de grado Magíster Scientarium en Diseño Urbano. Universidad Central de Venezuela. Caracas, Venezuela.

KOOLHAAS, Rem (2007) Espacio Basura. Editorial Gili SL. Barcelona, España.

KOSTOF, Spiro (1999) The city assembled. Bulfinch Press. Boston, EE. UU.

KOSTOF, Spiro (1993) The city shaped. Bulfinch Press. Boston, EE. UU.

LASALA, Ana (2007). "La calle. Lugar de enlace y encuentro". Trabajo de Ascenso para optar al escalafón de profesor asistente. Universidad Central de Venezuela. Caracas, Venezuela.

LASALA, Ana (2011). "En la calle: aportes al espacio urbano desde estrategias de proyecto". Trabajo de grado Magíster Scientarium en Diseño Arquitectónico. Universidad Central de Venezuela. Caracas, Venezuela.

LYNCH, Kevin (2008) La imagen de la ciudad. Editorial Gustavo Gili SL. Barcelona, España. MARCANO, Frank (1994). "Cascos urbanos: espacio de reflexión. Los cascos de Chacao, Baruta y el Hatillo". En: Revista Urbana. Instituto de Urbanismo, Universidad Central de Venezuela. Caracas, Venezuela.

MARTÍNEZ, Emilio (2003). "La significación social de los espacios públicos". En: Colección Mediterráneo Económico: "Ciudades, arquitectura y espacio urbano". Caja Rural Intermediterrámea. Almería, España.

MARTÍNEZ, Miguel (2010) Ciencia y arte en la metodología cualitativa. Editorial Trillas. México D. F., México.

MATEO, Josep Lluís (1995) En el límite. Textos instrumentales. Editorial Gustavo Gili SL. Barcelona, España.

PÉREZ, Edmundo (2000). "Paisaje urbano en Nuestras Ciudades". En: Bitácora UrbanoTerritorial. Bogotá D. C., Colombia.

PÉREZ DE TUDELA, Jorge (1992). "Hermenéutica y totalidad. Las razones del círculo". En: Anales del Seminario de Maaftsica. Universidad Complutense. Madrid, España. POSANI, Juan Pedro (1994). “¿Dónde está el norte?”. En: Debate y disquisiciones sobre el anón y el cambur. Ediciones de la Biblioteca de Arquitectura. Caracas, Venezuela.

PUCHETTI, Roberto (2004). "Memoria y lugar interacción y propuesta: proyecto arquitectónico en el borde Sur de la Ciudad Universitaria de Caracas como detalle del territorio". Trabajo de grado Magíster Scientarium en Diseño Arquitectónico. Universidad Central de Venezuela. Caracas, Venezuela.

RIBAS Y PIERA, Manuel (2003). "Paisaje y ciudad”. En: Ciudades: Revista del Instituto Universitario de Urbanística de la Universidad de Valladolid. Valladolid, España.

RUBY, Llika; RUBY, Andreas (2006) Grounscapes. El reencuentro con el suelo en la arquitectura contemporánea. Editorial Gustavo Gili SL. Barcelona, España. 
SORKIN, Michael (1998). "Eleven Tasks for Urban Design”. Urban Design: Practices, Pedagogies. Master of Urban Design - Briefing Materials. Columbia University. New York, EE. UU.

VEGAS, Federico (2007) La Ciudad y el deseo. Fundación Bigott. Caracas, Venezuela. VELASCO ROMANO, Joaquín (2003). "Desarrollo sostenible y paisaje". En: Ciudades: Revista del Instituto Universitario de Urbanística de la Universidad de Valladolid. Valladolid, España.

VON DER HEYDE, Cristina (2007). "Intersticios Urbanos". Trabajo de Ascenso para optar al escalafón de profesor asistente. Universidad Central de Venezuela. Caracas, Venezuela. 